\title{
OMAE2011-50067
}

\section{EXPERIMENTAL STUDY OF EROSION THRESHOLD OF RECONSTITUTED SEDIMENTS}

\author{
Zhihui Ye \\ School of Civil and Resource Engineering \\ The University of Western Australia \\ Perth, Western Australia 6009, Australia
}

\author{
Liang Cheng \\ School of Civil and Resource Engineering \\ The University of Western Australia \\ Perth, Western Australia 6009, Australia
}

\author{
Zhipeng Zang \\ Institute of Mechanics, Chinese Academy of Sciences \\ Beijing, 100080, China
}

\section{ABSTRACT}

Understanding of fundamental erosion characteristics of seabed sediments on which pipelines and other structures are founded is critical for the design of these facilities. The erosion threshold condition of cohesive sediments is not well understood because of the complexity and variability of natural sediments. Most of the existing methods for evaluating the erosion behaviours of seabed sediment are often applicable to the certain particular sediment types and test conditions. There appears to be a need for more research efforts in this area. In present research, the threshold of motion of four moderately consolidated mixtures was tested under unidirectional currents using a testing facility. Three threshold shear stress increase modes were observed, including initial increase mode, steady increase mode and equilibrium mode as mass content of mud $\mathbf{P}_{\mathrm{m}}$ increases. A dimensionless threshold shear stress $\tau^{*}$ is proposed to quantify the shear strength of these reconstituted mixtures, coupled with variation of coarse particle size. Finally, a predicting model is proposed to illustrate the trend of erosion threshold of the four mixtures as a function of mud weight content. Further understanding of erosion threshold can rely on the various consolidation conditions and different coarse and fine materials inputted in the mixture.

\section{INTRODUCTION}

Natural seabed sediments are often classified as non-cohesive sediments and cohesive sediments based on electrochemical bond between sediment particles. While in the field situation, sediments are widely found as a mixture of both types of particles in the form of homogeneous or laminated bed (Panagiotopoulos et al., 1997). This leads to complexity and difficulty in proposing a universal applicable evaluation method to characterize the erosion process of seabed sediment in marine system.

The erosion process is mainly characterised by erosion threshold and erosion rate. For non-cohesive sediments, the resistance to erosion mainly provided by gravity, friction force which are influenced by grain particle size and density, etc. With regard to cohesive sediment, the electrochemical force between particles or flocs is dominant. The previous research efforts have been contributed to correlate the soil basic physical parameters such as clay mineral, bed composition, and packing situation and shear strength of sediment. Several published experimental results show that erosion threshold of cohesive sediment is dependent on particle size, fine material, bulk density and shear strength of sediments (Mehta and Lee, 1994; Mitchener and Torfs, 1996; Panagiotopoulos et al., 1997; Dou, 2000 ). It is well recognised that various evaluation methods for erosion threshold of cohesive sediment are normally only appropriate for certain sediment types and conditions under which the methods were derived. Further research work is needed for better understanding of the erosion behaviours of cohesive sediments. For this purpose, the present research focuses on the erosion threshold of reconstituted sand and mud mixtures, correlating the threshold shear stress with certain soil basic parameters, i.e., particle size, bed composition and consolidation conditions of the sediment.

\section{THRESHOLD OF MOTION}

Threshold of motion is the beginning of sediment transport, which is the process that sediment particles move or detach from original seabed. Assuming the original seabed is flat without any features, non-deformable with a unidirectional 
steady flow exerting on sediment at flow rate under critical velocity. The net upward hydrodynamic force acts on the lower edge of a particle or a floc due to the velocity difference between surface and lower layer of the particles. This upward force keeps increasing as the velocity is increased until pits or cracks appear at bed surface, which indicates that the external water is able to follow these small paths to reach internal pore water. Meanwhile some small vortices may form around the cracks or pits and enhance the effects of drag $F_{D}$ and lift $F_{L}$ forces on the surface of sediment, causing the failure of bonds of flocs along the cracks. The threshold of motion happens when the electrochemical bond is broken by hydrodynamic force, after that the grain is transported by water. A sketch of various forces acting on a particle is illustrated in Figure 1.

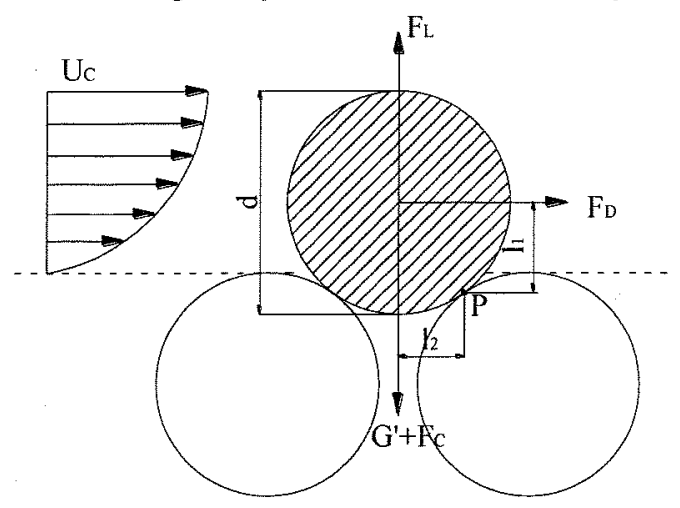

Figure 1 Schematic illustration of forces On a grain

The initial motion of a particle is determined by the equilibrium of four forces acting on the particle: drag force $F_{D}$, lift force $F_{L}$, buoyant weight $G^{\prime}$ and cohesion force $F_{c}$ (if any), as shown in Figure 1. The critical state of particle can be analysed through moment balance (Dou, 2000; Mehta and Lee, 1994; Righetti and Lucarelli, 2007; Ternat, et, al., 2008). The expression for the joint forces exerting on the particle at critical condition based on moment balance is:

$$
F_{D} \cdot l_{1}=\left(G^{\prime}+F_{c}-F_{L}\right) \cdot l_{2}
$$

where $l_{1}$ and $l_{2}$ are arms of drag and lift forces to overturning point $P$ (Figure 1). The buoyant gravity is the function of grain shape factor $\mathrm{k}_{\mathrm{G}}$, submerged particle weight and particle size, and the expression for buoyant gravity is written as $G^{\prime}=k_{G}\left(\rho_{s}-\rho\right) g d^{3}$. Drag and lift forces by fluid flow are regarded as functions of grain particle size and friction velocity, $F_{D}=k_{D} \rho u_{*}^{2} d^{2}$ and $F_{L}=k_{L} \rho u_{*}^{2} d^{2}$, where $\mathrm{k}_{\mathrm{D}}$ and $\mathrm{k}_{\mathrm{L}}$ drag and lift coefficients, and $u_{*}$ is bottom friction velocity. Letting $\lambda=l_{1} / l_{2}$ and arranging Eq. (1) by substituting the forces with above expressions, the equation can be written as

$$
\tau_{c r}=\rho u_{*}^{2}=\frac{k_{G}\left(\rho_{s}-\rho\right) g d}{\left(k_{D} \lambda+k_{L}\right)}+\frac{F_{c}}{\left(k_{D} \lambda+k_{L}\right) d^{2}}
$$

where $F_{c}$ refers to cohesion force as a result of comprehensive interactions between coarse and fine sediment particles. The first term on the right hand side of Eq. (2) is non-cohesive bed shear stress $\tau_{s}=\frac{k_{G}\left(\rho_{s}-\rho\right) g d}{\left(k_{D} \lambda+k_{L}\right)}$, which has been commonly related to dimensionless Shields parameter (Shield, 1936) and dimensionless grain particle (Van Rijn, 1993). To factor the $\tau_{\mathrm{s}}$ from Eq. (2), then $\tau_{\mathrm{cr}}$ can be represented as

$$
\tau_{c r}=k \cdot \tau_{s}
$$

where $\quad k=1+\frac{F_{c}}{k_{G}\left(\rho_{s}-\rho\right) g d^{3}}$ is a comprehensive coefficient which will be experimentally determined. According to the expression, coefficient $\mathrm{k}$ varies with the ratio of cohesive force over coarse grain buoyant weight.

The tests have been designed to quantify the effect of the shear strength of seabed sediment on parameter $k$. Erosion tests are conducted on four reconstituted mixtures with four different sands and kaolin clay.

\section{EXPERIMENT}

Four sets of experiments were carried out on mixtures of four different uniform sands with increasing kaolin clay content. The sands used are calcareous sand, coarse sand (RC), superfine sand (SF) and G12-20 sand, and median grain size for these four sands are $0.345,0.498,0.159$ and $1.322 \mathrm{~mm}$ respectively. The basic parameters for kaolin clay are reported in Table 1 .

Table 1 Kaolin clay properties

\begin{tabular}{cc}
\hline Sample & Kaolin \\
\hline Particle density $\rho_{\mathrm{s}}\left(\mathrm{kg} / \mathrm{m}^{3}\right)$ & 2575.8 \\
Median grain size $\mathrm{d}_{50}(\mu \mathrm{m})$ & 1.45 \\
Plastic Limit PL $(\%)$ & 33.6 \\
Liquid Limit LL $(\%)$ & 56.9 \\
Plasticity Index PI $(\%)$ & 23.3 \\
\hline
\end{tabular}

\subsection{Sample preparation}

The mixtures were mechanically stirred with water for ten minutes to achieve a homogeneous mixture. The mixtures were then put into a cylinder of $72 \mathrm{~mm}$ internal diameter for consolidation via a weight and hanger system. The samples were consolidated under $8 \mathrm{kPa}$ pressure for 1 to 2 days till no water was drained out and then cut into two halves for erosion test. To quantify the consolidation degree of reconstituted samples, a consolidation coefficient $\alpha_{c}$ is proposed by Allersma (1988) and cited by Van Ledden et al. (2003) based on the measurements of field samples. It is correlated to dry density $\rho_{d}$ 
and sand weight fraction $\mathrm{P}_{\mathrm{sa}}$ to denote the consolidation situation of mixed samples:

$$
\rho_{d}=480 \alpha_{c}+\left(1300-280 \alpha_{c}\right) P_{s a}^{0.8}
$$

Where $\rho_{\mathrm{d}}$ is dry density of reconstituted mixture,

$\alpha_{c}$ is the consolidation coefficient,

$\mathrm{P}_{\mathrm{sa}}$ is sand fraction of mixture.

The dry density is plotted against sand content (\%) in Figure 2 together with $\alpha_{c}$ value range. The solid lines in Figure 2 represent different values of $\alpha_{c}$ from 0 (fresh bed) to 2.4 (consolidated bed), and each line stands for same consolidation level. According to Figure 2, the consolidation degree of mixtures for the present tests is around $\alpha_{c}=2.0$. The samples were tested with variations of sand and clay content at the same consolidation level.

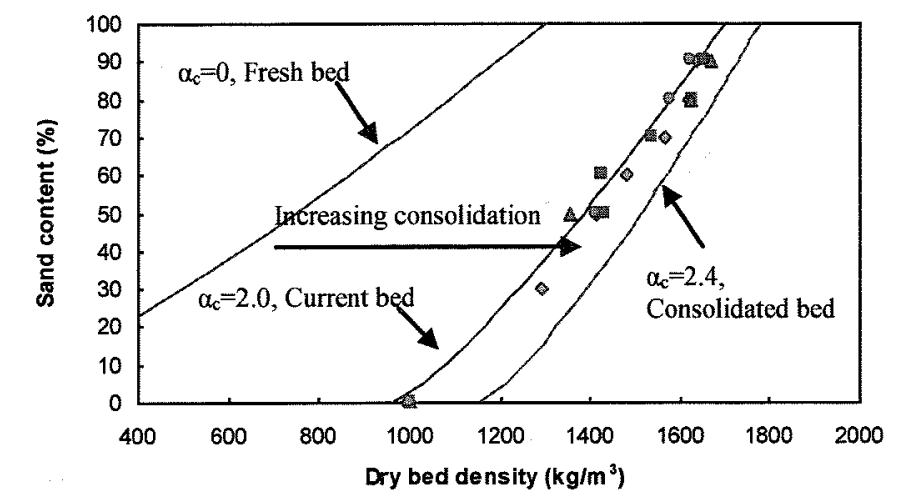

- Calcareous sand/kaolin mixture G1 RC sand/kaolin mixture G2

$$
\triangle \mathrm{SF} \text { sand/kaolin mixture G3 G12-20 sand/kaolin mixture G4 }
$$

Figure 2 Variation of dry density with weight fraction of sand for sand/mud mixtures

\subsection{Equipment setup}

A closed-loop Mini O-tube (MOT) facility is employed to carry out the proposed tests in the present research. This facility comprises of a closed circular channel of water driven by a turbine, with an enlarged test section in which experiments were conducted. The size of test cross-section of the MOT is $200 \mathrm{~mm}$ by $200 \mathrm{~mm}$, and the length of the test section is $1800 \mathrm{~mm}$. The turbine runs at a constant speed to provide steady flow and oscillates to simulate wave action, and can generate oscillatory flows superposed on unidirectional currents. The test section is able to accommodate the samples via an embedded semicircular sample holder with a width of $72 \mathrm{~mm}$ and a length of $300 \mathrm{~mm}$. As shown in Figure 3 (a), an Acoustic Doppler Velocimeter (ADV) is used to measure flow velocity in the Otube. In order to observe the initial motion of sediments, a 3D laser camera is adopted to observe and measure threshold of motion and erosion depth of sediments.

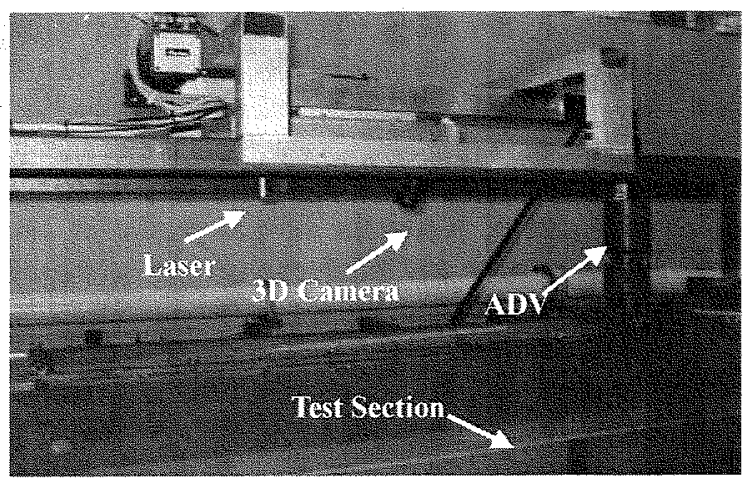

(a) Mini O-tube testing system

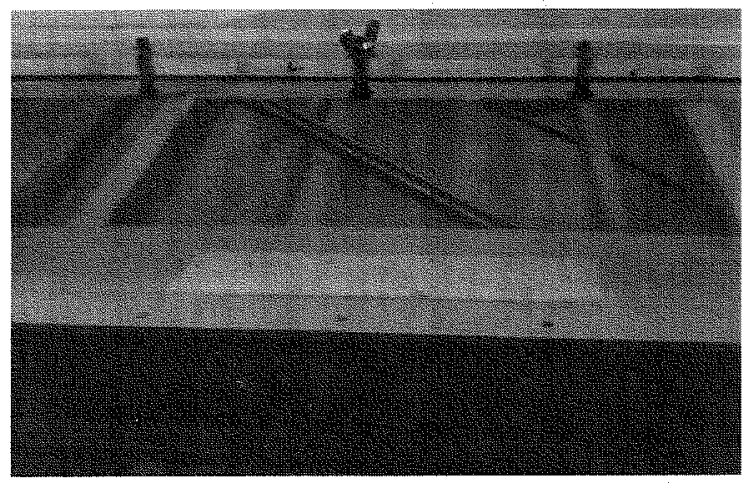

(b) Sample in the test section

Figure 3 Experiment setup for erosion threshold testing

Each consolidated soil sample to be tested was cut into two even semicircular halves for two independent runs of test. A half sample is placed in a sample holder on the smooth bed of the test section of MOT. The reconstituted sample was submerged in water for approximately 12 hours to allow it to adjust itself to an equilibrium stable situation. The surface of the soil sample was kept flush with the smooth channel bed as shown in Figure 3 (b). The MOT was then filled with water. Attention was paid to ensure that the sediment is not disturbed during the filling and no air is trapped in the tank after the filling.

\subsection{Test procedure}

The present tests on reconstituted samples were conducted under steady current flow conditions. The velocity increment was $0.05 \mathrm{~m} / \mathrm{s}$ at the initial stage of the test and this was reduced to $0.01 \mathrm{~m} / \mathrm{s}$ at a later stage when small amount of sediments become unstable. The sample is exposed to each velocity for 10 minutes before velocity is increased. This process is repeated until significant erosion of the sample is observed. The threshold motion of sediment (surface erosion) is defined as the majority amount of surface particles of sediments begin to move, or a few flocs for cohesive sediment begin to flake off. An Acoustic Doppler Velocimeter (ADV) was adopted to measure the critical velocity simultaneously (Figure 3 (a)). The velocity corresponding to the critical condition is defined as the threshold velocity. The shear stress corresponding to this velocity is referred to as threshold shear stress. To quantify the 
amount of erosion, the sample surface is scanned by a SICK ranger 3-D laser scanner before and after each test. The scanned surface data were processed to determine the erosion depth and variation of seabed morphology (see Figure 4 ). The scanned profile for mixture $50 \%$ calcareous and $50 \%$ kaolin clay is presented in Figure 4, where the surface profile of sample is scanned before erosion and after erosion. By comparing the figure (a) and (b), some scour holes are found at the middle part of sample after erosion. Moreover, drastic scouring at the upstream boundary was observed in test and it is reflected in the scanned figure (b) as well, which is mainly due to a local scouring around boundary of sample.

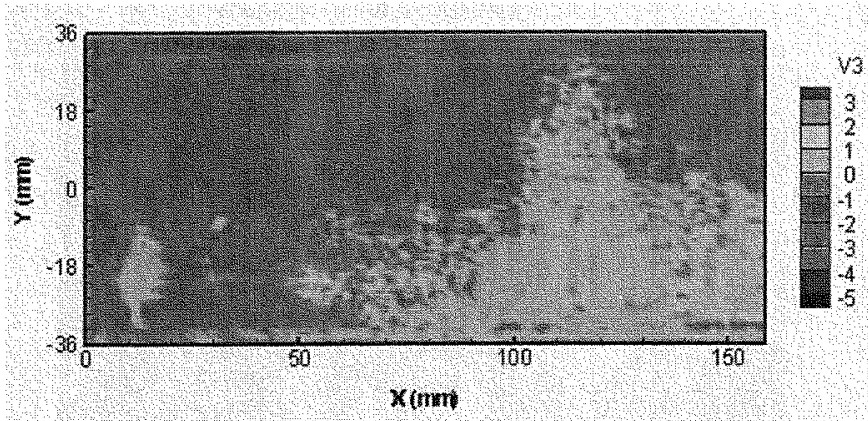

(a) Scanned sediment surface before erosion

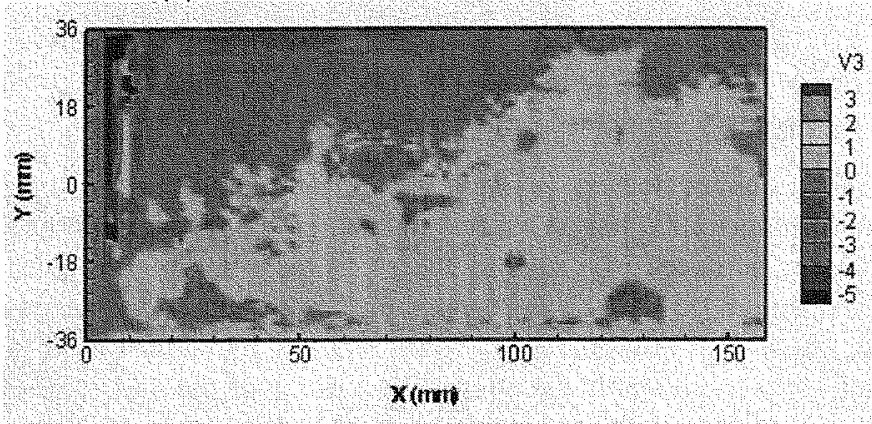

(b) Scanned sediment surface after erosion

Figure 4 Scanned images of sediment surface before erosion (a) and after erosion (b) for mixture of $50 \%$ calcareous sand and $50 \%$ kaolin clay, where $V 3$ represents the height of sample in $\mathrm{mm}$.

\section{RESULTS AND DISCUSSION}

In the tests, the mud content $\mathrm{P}_{\mathrm{m}}$ ranges from $0 \%$ to $100 \%$. The critical shear stress $\tau_{\mathrm{cr}}$ is calculated by $\tau_{\mathrm{cr}}=\rho u_{*}{ }^{2}$, where $\rho$ is the water density $\left(1000 \mathrm{~kg} / \mathrm{m}^{3}\right)$, and $\mathrm{u}^{*}$ is the bottom friction velocity. The velocity profile in $z$ direction $(z$ is the distance from certain point to the sample surface) in the MOT was found to follow a logarithmic profile

$$
U(z)=\frac{u_{*}}{\kappa} \ln \left(\frac{z}{z_{0}}\right)
$$

where $u_{*}$ is bottom friction velocity, $\kappa$ is von Karman's constant which equals 0.40 and $z_{0}$ is bed roughness length. The bed roughness length $z_{0}$ is determined using the following formula (Christoffersen and Jonsson, 1985)

$$
z_{0}=\frac{k_{s}}{30}\left[1-\exp \left(\frac{-u_{*} k_{s}}{27 v}\right)\right]+\frac{v}{9 u_{*}}
$$

where $v$ is the kinematic viscosity of water. The Eq. (6) is valid for all hydrodynamic flow conditions, including hydrodynamically smooth, transitional or rough flow.

Prior to erosion tests on reconstituted samples, calibration tests on four sands have been done and the test results were compared with Shields diagram and previous experimental data to justify the validity of the testing procedure. Table 2 shows results of threshold shear stresses and threshold Shields parameters determined from the calibration tests. In the table, $\rho_{\mathrm{s}}$ is sediment grain density, $d_{50}$ is median size of sediments, $\tau_{c r}$ is the threshold shear stress under steady currents (use average value of two runs) and $\theta_{\mathrm{cr}}$ is corresponding Shields parameters, $D_{*}$ is the dimensionless grain size, and $R_{*}$ is grain Reynolds number. The original Shields curve was plotted in the form of $\theta_{\text {cr }}$ (the threshold Shields parameter) versus grain Reynolds number $\operatorname{Re}_{*}=u_{*} d / v$. Since the unknown $u_{*}$ appears on both coordinates, more efforts have been contributed to provide direct mathematical transformations thereafter. The present research used a dimensionless particle size $D_{*}$ (Soulsby, 1997) instead of $\operatorname{Re}_{*}$ to plot against $\theta_{c r}$, which avoids the iterations and is easier for practical application. The Shield parameter $\theta_{\mathrm{cr}}$ obtained from experiments was plotted against dimensionless D* in Figure 5, comparing with Shields curve (Soulsby, 1997) with previous experimental data envelope as reference. The expressions for Shields parameter $\theta_{\mathrm{cr}}$ and dimensionless grain size $\mathrm{D}$ * are given by

$$
\begin{aligned}
& \theta_{c r}=\frac{\tau_{c r}}{g\left(\rho_{s}-\rho\right) d} \\
& D_{*}=\left[\frac{g(s-1)}{v^{2}}\right]^{1 / 3} d
\end{aligned}
$$

It is observed that the present experimental data fall well within the range of experimental data that were used to derive Shield curve. The grain Reynolds number can be used to identify the experienced flow type which ranges from 2 to 28 for transitional flow, and under 2 or above 28 for hydrodynamically smooth or rough flow correspondingly. The value of grain Reynolds numbers shows that for G12-20 sand is hydrodynamically rough, for calcareous sand and RC sand are transitional states and for SF sand is hydrodynamically smooth.

Table 2 Parameters and experimental data of four sands 


\begin{tabular}{|c|c|c|c|c|c|c|}
\hline sample & $\begin{array}{c}\rho_{s} \\
\left(\mathrm{kglm}^{3}\right)\end{array}$ & $\begin{array}{c}d_{50} \\
(m m)\end{array}$ & $\begin{array}{c}\tau_{c r} \\
\left(\mathrm{~N} / \mathrm{m}^{2}\right)\end{array}$ & $\theta_{c r}$ & $D^{*}$ & Re* \\
\hline SF sand & 2620 & 0.159 & 0.185 & 0.0732 & 3.996 & 2.162 \\
\hline $\mathrm{RC}$ sand & 2627 & 0.498 & 0.279 & 0.0351 & 12.534 & 8.313 \\
\hline Calcareous sand & 2732 & 0.345 & 0.224 & 0.0383 & 8.866 & 5.168 \\
\hline G12-20 & 2640 & 1.322 & 0.700 & 0.0330 & 33.362 & 34.989 \\
\hline
\end{tabular}

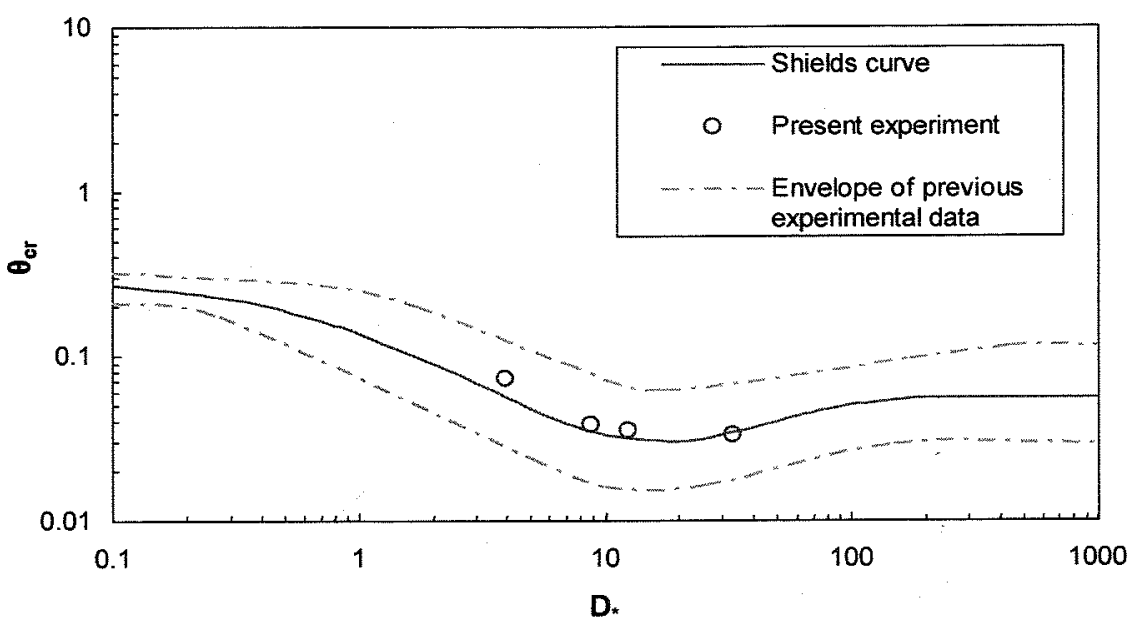

Figure 5 Threshold of motion of sands under currents

Based on the outcome of the calibration tests, it is concluded that the mini O-tube is suitable for erosion testing under steady current conditions. After calibration tests, the erosion tests are conducted on reconstituted samples under steady current flow condition. The threshold velocity is simultaneously captured by ADV, and then the friction velocity $u_{*}$ is calculated by Eq.(5) and (6). The threshold shear stress $\tau_{\text {cr }}$ is then determined by $\tau_{\mathrm{cr}}=\mathrm{\rho u}_{*}{ }^{2}$. The composition of samples are determined by the mass fraction of particles in different size range, including clay fraction $\mathrm{P}_{\mathrm{cl}}$, silt fraction $\mathrm{P}_{\mathrm{si}}$, sand fraction $\mathrm{P}_{\mathrm{sa}}$ and mud fraction $P_{m}$ (sum of $P_{c l}$, and $P_{s i}$ ). The particle size range for clay is under $2 \mu \mathrm{m}, 2-62 \mu \mathrm{m}$ for silt and $62 \mu \mathrm{m}-2 \mathrm{~mm}$ for sand. The composition and packing condition of mixtures are reported in Table 3, where $\mathrm{P}_{\mathrm{cl}}, \mathrm{P}_{\mathrm{si}}, \mathrm{P}_{\mathrm{sa}}$ and $\mathrm{P}_{\mathrm{m}}$ represent mass fraction of clay, silt, sand and mud, $\rho_{\mathrm{d}}$ is dry bulk density, $w$ stands for water content, $\mathrm{u}_{50}$ is the measured threshold velocity at $50 \mathrm{~mm}$ above bed, $u_{*}$ is threshold bottom friction velocity and $\tau_{\mathrm{cr}}$ is threshold shear stress. Group 1 to 4 represent mixtures of calcareous sand, RC sand, SF sand and G12-20 sand with kaolin clay respectively. Based on the same consolidation level, the emphasis is focused on the variation of threshold shear stress as a function of mud content, $\tau_{\mathrm{cr}}$ is plotted against mud content for four groups of mixture in Figure 6. 
Table 3 Parameters and experimental data of four groups of mixtures

\begin{tabular}{|c|c|c|c|c|c|c|c|c|c|c|c|c|c|}
\hline \multirow{2}{*}{ Group } & \multirow{2}{*}{ No. } & \multirow{2}{*}{$\mathbf{P}_{\mathrm{cl}}(\%)$} & \multirow{2}{*}{$P_{s i}(\%)$} & \multirow{2}{*}{$P_{\text {sa }}(\%)$} & \multirow{2}{*}{$P_{m}(\%)$} & \multirow{2}{*}{$\rho_{d}\left(\mathrm{~kg} / \mathrm{m}^{3}\right)$} & \multirow{2}{*}{$w(\%)$} & \multicolumn{2}{|c|}{$\mathrm{u}_{50}(\mathrm{~m} / \mathrm{s})$} & \multicolumn{2}{|c|}{$\mathrm{u}_{*}(\mathrm{~m} / \mathrm{s})$} & \multicolumn{2}{|c|}{$\tau_{c r}\left(N / m^{2}\right)$} \\
\hline & & & & & & & & Run1 & Run2 & Runl & Run2 & Runl & Run2 \\
\hline \multirow{8}{*}{ G1 } & 1 & 0.0 & 0.0 & 100.0 & 0.0 & - & - & 0.2885 & 0.2877 & 0.0150 & 0.0149 & 0.224 & 0.223 \\
\hline & 2 & 6.0 & 4.0 & 90.0 & 10.0 & 1638.40 & 0.21 & 0.4281 & 0.4310 & 0.0220 & 0.0222 & 0.484 & 0.491 \\
\hline & 3 & 12.0 & 8.0 & 80.0 & 20.0 & 1616.85 & 0.21 & 0.6840 & 0.6857 & 0.0352 & 0.0353 & 1.242 & 1.248 \\
\hline & 4 & 18.0 & 12.0 & 70.0 & 30.0 & 1565.35 & 0.23 & 0.8807 & 0.8839 & 0.0446 & 0.0448 & 1.989 & 2.003 \\
\hline & 5 & 24.0 & 16.0 & 60.0 & 40.0 & 1478.26 & 0.36 & 0.9828 & 0.9874 & 0.0484 & 0.0487 & 2.347 & 2.347 \\
\hline & 6 & 30.0 & 20.0 & 50.0 & 50.0 & 1412.76 & 0.40 & 1.1246 & 1.1353 & 0.0498 & 0.0502 & 2.476 & 2.522 \\
\hline & 7 & 42.1 & 27.9 & 30.0 & 70.0 & 1293.48 & 0.48 & 1.3986 & 1.4209 & 0.0581 & 0.0590 & 3.380 & 3.479 \\
\hline & 8 & 60.1 & 39.9 & 0.0 & 100.0 & 999.03 & 0.73 & 1.5154 & 1.5211 & 0.0625 & 0.0627 & 3.909 & 3.936 \\
\hline \multirow{6}{*}{ G2 } & 9 & 0.0 & 0.0 & 100.0 & 0.0 & - & - & 0.3063 & 0.3035 & 0.0167 & 0.0165 & 0.279 & 0.273 \\
\hline & 10 & 6.0 & 4.0 & 90.0 & 10.0 & 1655.04 & 0.23 & 0.4439 & 0.4507 & 0.0242 & 0.0246 & 0.587 & 0.606 \\
\hline & 11 & 12.0 & 8.0 & 80.0 & 20.0 & 1627.55 & 0.24 & 0.6892 & 0.6815 & 0.0381 & 0.0376 & 1.450 & 1.417 \\
\hline & 12 & 18.0 & 12.0 & 70.0 & 30.0 & 1539.88 & 0.27 & 0.8710 & 0.8883 & 0.0483 & 0.0493 & 2.332 & 2.429 \\
\hline & 13 & 24.0 & 16.0 & 60.0 & 40.0 & 1424.70 & 0.32 & 0.9720 & 0.9931 & 0.0525 & 0.0537 & 2.756 & 2.882 \\
\hline & 14 & 30.0 & 20.0 & 50.0 & 50.0 & 1429.88 & 0.41 & 1.1270 & 1.1476 & 0.0544 & 0.0554 & 2.958 & 3.070 \\
\hline \multirow{4}{*}{ G3 } & 15 & 0.0 & 0.0 & 100.0 & 0.0 & - & - & 0.2739 & 0.2766 & 0.0136 & 0.0137 & 0.185 & 0.188 \\
\hline & 16 & 6.0 & 4.0 & 90.0 & 10.0 & 1666.17 & 0.21 & 0.3985 & 0.3987 & 0.0192 & 0.0192 & 0.369 & 0.369 \\
\hline & 17 & 12.0 & 8.0 & 80.0 & 20.0 & 1625.40 & 0.25 & 0.7205 & 0.7271 & 0.0336 & 0.0339 & 1.132 & 1.152 \\
\hline & 18 & 30.0 & 20.0 & 50.0 & 50.0 & 1355.92 & 0.35 & 1.3141 & 1.3247 & 0.0570 & 0.0574 & 3.243 & 3.294 \\
\hline \multirow{4}{*}{ G4 } & 19 & 0.0 & 0.0 & 100.0 & 0.0 & - & - & 0.3976 & 0.3984 & 0.0265 & 0.0265 & 0.700 & 0.703 \\
\hline & 20 & 6.0 & 4.0 & 90.0 & 10.0 & 1624.86 & 0.22 & 0.6646 & 0.6399 & 0.0444 & 0.0427 & 1.972 & 1.827 \\
\hline & 21 & 12.0 & 8.0 & 80.0 & 20.0 & 1579.89 & 0.29 & 0.8255 & 0.8209 & 0.0547 & 0.0543 & 2.987 & 2.954 \\
\hline & 22 & 30.0 & 20.0 & 50.0 & 50.0 & 1414.45 & 0.37 & 1.0074 & 1.0250 & 0.0618 & 0.0629 & 3.814 & 3.950 \\
\hline
\end{tabular}

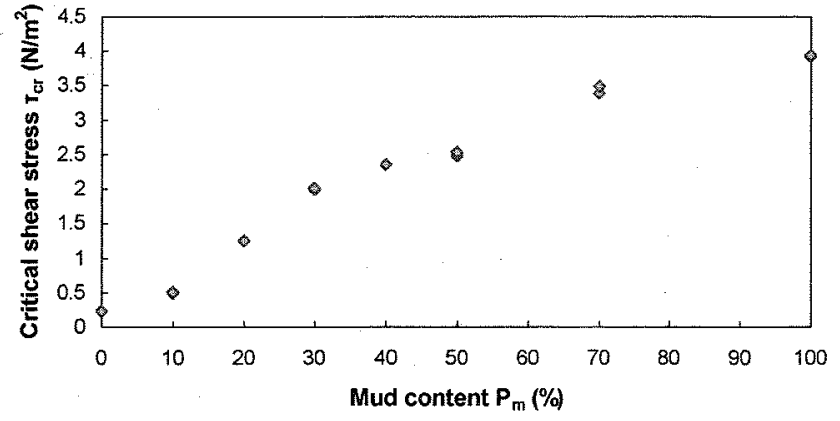

(a) Calcareous sand and kaolin clay mixture (Group 1)

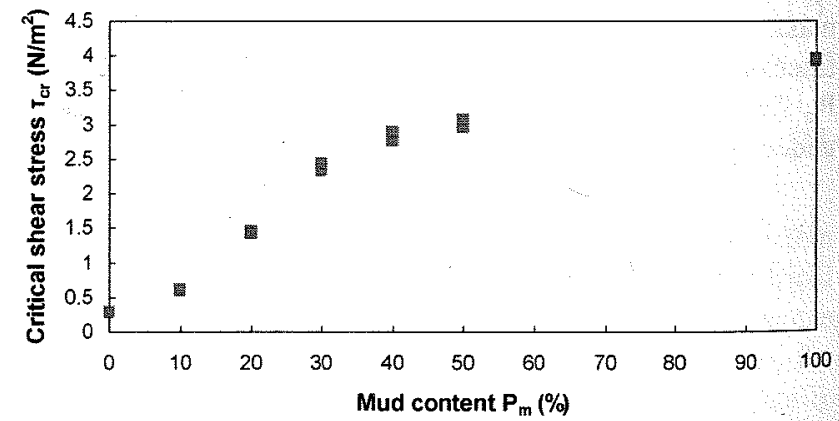

(b) RC sand and kaolin clay mixture (Group 2) 


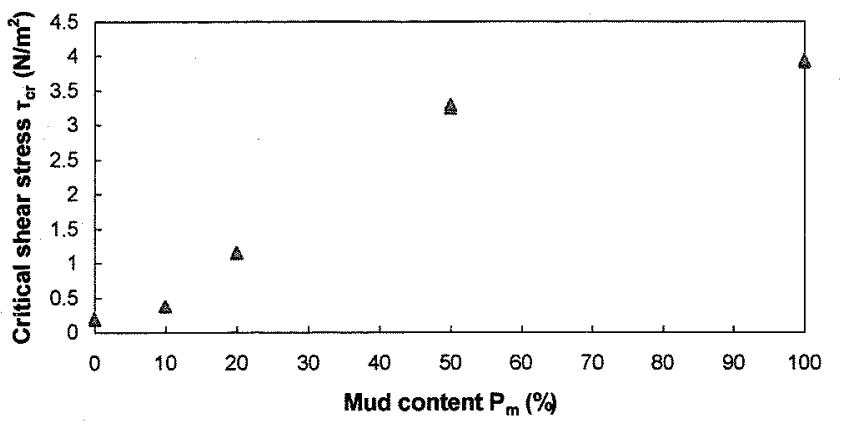

(c) SF sand and kaolin clay mixture (Group 3)

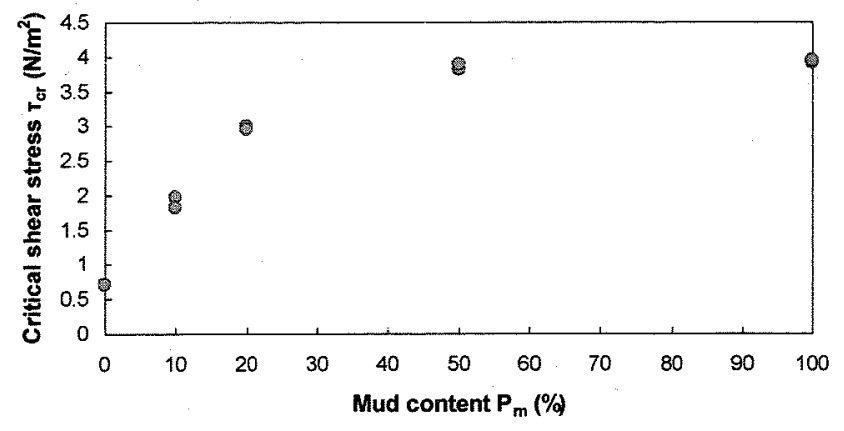

(d) G12-20 sand and kaolin clay mixture (Group 4)

Figure 6 Threshold shear stress vs. mud content (\%) for four groups of mixtures

As shown in Figure 6 , the critical shear stress $\tau_{\mathrm{cr}}$ for four mixtures ranges from $\tau_{s}$ (critical shear stress of pure sand) to $3.92 \mathrm{~N} / \mathrm{m}^{2}$ corresponding to mud fraction increasing from 0 to $100 \%$, with a corresponding clay fraction from $0-60 \%$. It is noted from experimental data that there are generally three stages of growth of critical shear stress $\tau_{\mathrm{cr}}$ as mud fraction $\mathrm{P}_{\mathrm{m}}$ increases as shown in Figure 7. This behaviour is shown schematically in Figure 7 where S1, S2 and S3 refer to Stage 1, 2 and 3 of threshold shear stress variation with clay content. In the first stage, where the mud fraction ranges from 0 to $10-$ $20 \%$ (depends on different soil types), the increase rate of $\tau_{\mathrm{cr}}$ with mud content is small compared with the increase rate observed in the $\mathrm{S} 2$ stage. With regard to mixtures with $10 \%$ of mud fraction, unlike the incipient erosion of pure sand which can be characterized by significant particles moving as bedload, it is observed from the test that some of flocs were detached from bed. It is implied that the electrochemical bond begins to take effects in binding the coarse grains. Particularly, the stage 1 experiences a notable shorter range for G12-20 sand/kaolin mixture than other three groups. It reflects a remarkable difference of erosion resistance between mixtures with median/fine sand and coarse sand.

In $\mathrm{S} 2$ stage where the mud fraction ranges from $10-20 \%$ to $50-$ $60 \%, \tau_{\mathrm{cr}}$ increases with $\mathrm{P}_{\mathrm{m}}$ more rapidly than that observed in Stage 1 . It was observed that soil samples were eroded by flocs or aggregations. The variation $\tau_{\mathrm{cr}}$ with mud content in Stage 2 appears to be a linear trend. This suggests that the binding force around coarse grain from fine material strongly affects the erosion resistance of the mixture.

For mixtures with higher mud fraction (at the range of $50 \%$ to $100 \%$ ), there is an indication that the value of $\tau_{\mathrm{cr}}$. only increases slightly for most of the mixtures. It can be inferred that a turning point must exist at the end of second stage, which represent the starting of the third stage. This stage is characterised by the magnitude of $\tau_{\mathrm{cr}}$ gradually approaches the final value of threshold shear stress for $100 \% \mathrm{mud}$. This suggests that the erosion behaviour of sand/mud mixture with high percentage mud content $(>50-60 \%)$ is similar to that of sediment with fine particles only $\left(\mathrm{d}_{50}<62 \mu \mathrm{m}\right)$.

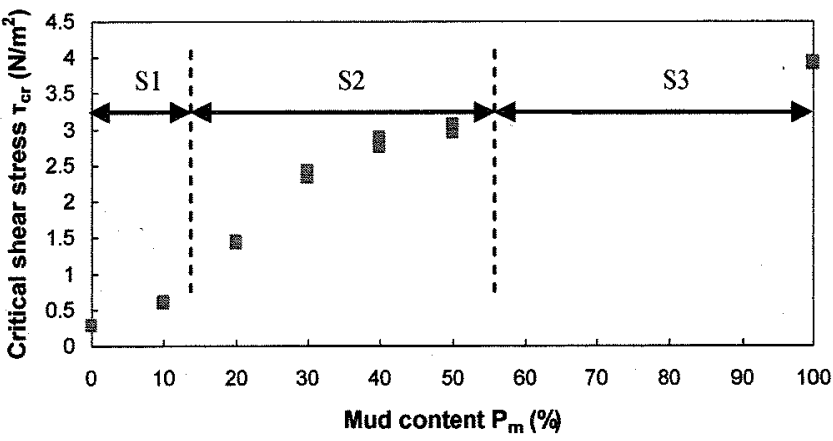

Figure 7 Schematic trend of three stages of $T_{c r}$ variations

The erosion behaviour of mixtures observed in the present tests was also observed previously by Mitchener and Torfs, 1996 (Figure 8). In their research, flume tests were conducted on threshold of motion of reconstituted homogeneous mixtures with cohesive sediments was kaolinite, montmorillonite and two natural estuary sediments. The bulk density was kept as constant as the fine particles were added. Four types of fine materials with $d_{50}$ less than $62 \mu \mathrm{m}$ were added in the sand ranged from $0-30 \%$ with $d_{50}$ of $230 \mu \mathrm{m}$ and the corresponding critical shear stresses for all samples ranged from 0.35 to $2.6 \mathrm{~N} / \mathrm{m}^{2}$. The boundary between stage 1 and stage 2 is around $5 \%$ mud content with minor variation as different fine materials added. There is indication that relationship between critical shear stress $\tau_{c r}$ and mud content $P_{m}$ is curved and unsteady with very few decreases. The $\tau_{\mathrm{cr}}$ appears more linearly increase with higher mud content. The critical shear stress significantly increases when higher amount of fine particles added. They concluded that although the gradient of $\tau_{\mathrm{cr}}$ value varies for different cohesive sediment, but the anchor point ( $0 \%$ mud fraction) is the same as the same sand was used. The increase of critical shear stress with mud content was reported to experience two stages, similar to the behaviours observed in the Stage 1 and Stage 2 of the present tests. Erosion behaviour in stage 3 was not reported because 
the maximum mud content was about $28 \%$ in their tests, as shown in Figure 8.

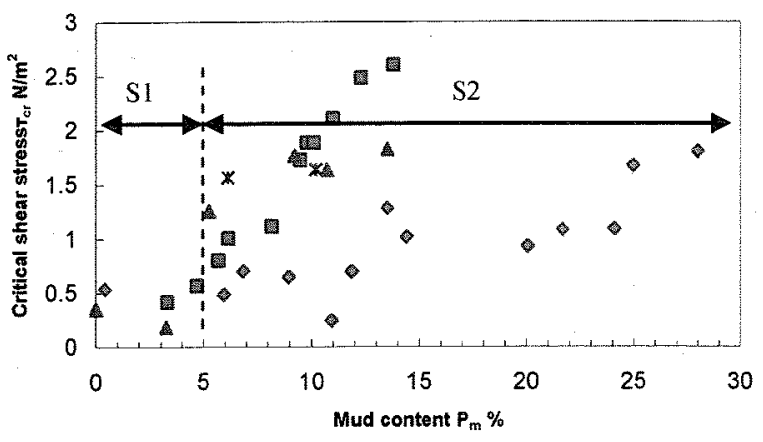

- Montmorillonite/sand Kaolinite/sand $x$ Scheldt mud $1 /$ sand 4 Scheldt mud $2 /$ sanc

Figure 8 Threshold shear stress vs. mud content $\%$ for different types of cohesive material (after Mitchener and Torfs, 1996)

The observed trends of the increase of the threshold shear stress with clay content in the present study can be represented by a logistic function (also known as the Verhulst model or logistic growth curve). Logistic function was originally studied by Pierre François Verhulst to model the population growth in 1840 s. It is often applied to model the "S-shaped" curve of growth of some variables. The initial stage of growth is approximately exponential and the growth slows when reaching at a saturating stage. This function has been widely used in research area of physics, chemistry, mathematics, ecology and medicine to demonstrate the growth type of research objects. To apply this function to model the growth of critical shear stress $\tau_{\mathrm{cr}}$, a dimensionless shear stress $\tau^{*}$ is proposed to enable the comparability of the four mixtures with different sands. The logistic function describing the dimensionless shear stress $\tau^{*}$ as function of mud fraction $\left(\mathrm{P}_{\mathrm{m}}\right)$ is suggested as

$$
\tau^{*}=k=\frac{c}{1+e^{-a P_{m}+b}}
$$

where $\tau^{*}$ is dimensionless shear stress and equals the comprehensive coefficient $\mathrm{k}$ which is defined in Eq. (3), $\mathrm{a}, \mathrm{b}$ and $c$ are sediment-specified coefficients, and $P_{m}$ is mud fraction in percentage.

The sigmoid curve was applied to model the growth of dimensionless $\tau^{*}$ against the increasing mud fraction for four mixtures and G1 mixtures as a typical example (Figure 9). The best-fit expressions are plotted and compared with measured data. The magnitude of the $\tau^{*}$ of kaolin clay for four mixtures is different because of the variation of the anchor point of $\tau_{\mathrm{cr}}$ for non-cohesive sand. The fitting curve well displays three stages of increasing characteristics of dimensionless critical shear stress as clay content is increased. It is worth noting that the $\tau^{*}$ of $\mathrm{G} 4$ mixtures have a relatively lower final value. Besides, their $\tau_{\mathrm{cr}}$ reach the saturated stage faster than other groups, at round $40 \%$ of mud content. It can be inferred that fine particles are more effective to bond the coarse grain to offer much stronger shear strength for coarse sand $(>0.6 \mathrm{~mm})$ and mud mixture.

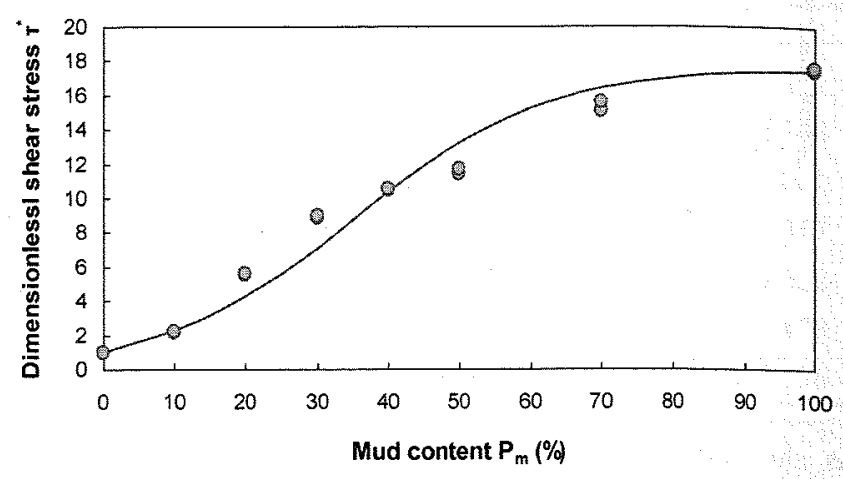

(a) Data fitting of dimensionless threshold shear stress vs. mud content for $\mathrm{G} 1$ mixtures

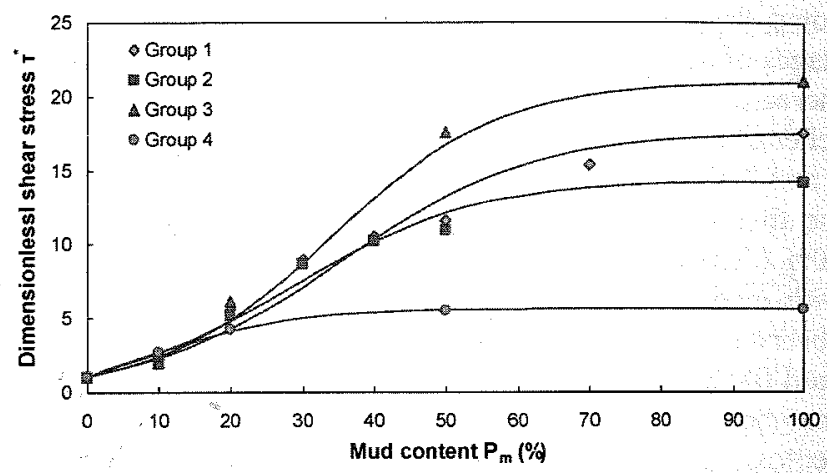

(b) Data fitting of dimensionless threshold shear stress vs. mud content for four mixtures

Figure 9 Dimensionless critical shear stress $\mathrm{T}^{*}$ as a function of mud fraction $P_{m}$ for $G 1$ and four mixtures

The mixture-specific coefficients a, b and c in Eq. (9) are understood to be dependent on original soil material properties and can be determined by regression analysis of test results. Considering that a space-filling process (Torfs, et al., 2000), the particle size is applied to investigate the filling and binding effect as coarse grain size varies in mixtures. Since the clay size is constant for all groups, the coarse grain particle size is linked with coefficients $a, b$ and $c$ in Figure 10. The best fit values of coefficients $a, b$ and $c$ for the present tests are reported in Table 4, and the modelling results of dimensionless critical shear stress $\tau^{*}$ are presented in Figure 10 , where $\mathrm{R}^{2}$ is square value indicating the accuracy of fting result. The coefficients $a, b$ and $c$ are highly dependent on the coarse grain size $\mathrm{d}_{\text {sand }}$ with $\mathrm{R}^{2}$ values larger than $93 \%$. 
Table 4 Best fit coefficients for four mixtures

\begin{tabular}{cccccc}
\hline Group No. & Mixture & $\mathbf{a}$ & $\mathbf{b}$ & $\mathrm{c}$ & $\mathbf{d}_{\text {sand }}$ (mm) \\
\hline 1 & Calcareous sand/Kaolin & 0.075 & 2.65 & 17.6 & 0.345 \\
2 & RC sand/Kaolin & 0.080 & 2.30 & 14.3 & 0.498 \\
3 & SF sand/Kaolin & 0.085 & 2.90 & 21.0 & 0.159 \\
4 & G12-20 sand/Kaolin & 0.110 & 1.20 & 5.6 & 1.322 \\
\hline
\end{tabular}

$a=0.030$ s a d 0.06

$\mathrm{b}=-1.243 \mathrm{~s} 6 \mathrm{df} 2.8 \varepsilon$

$\mathrm{c}=-12.72 \mathrm{~s} 9 \mathrm{~d}+22.0$

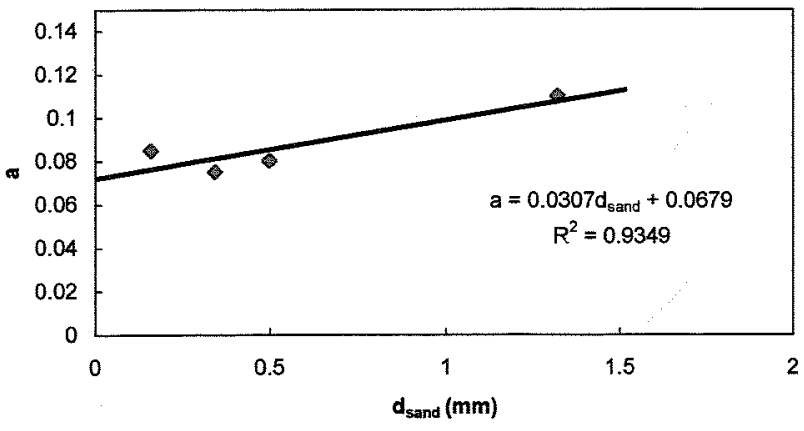

(a) Coefficient a vs. sand diameter $d_{\text {sand }}$

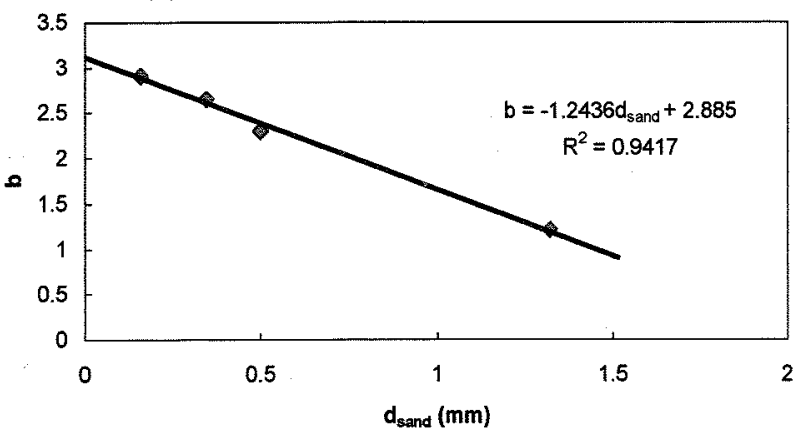

(b) Coefficient b vs. sand diameter $\mathrm{d}_{\text {sand }}$

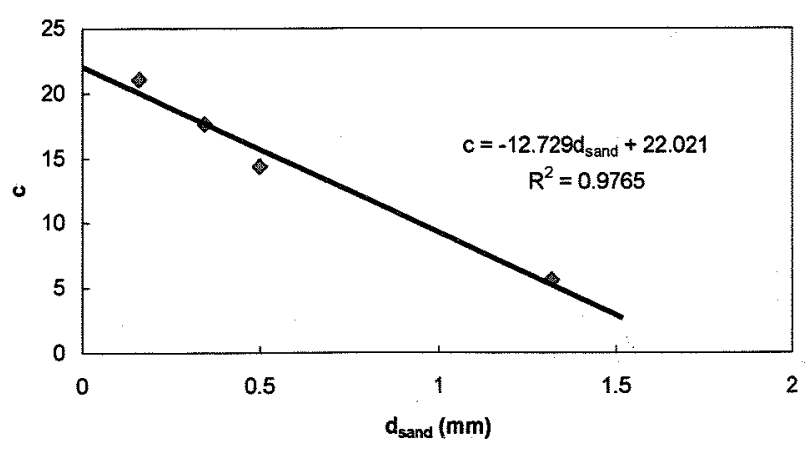

(c) Coefficient $c$ vs. sand diameter $d_{\text {sand }}$

Figure 10 Correlations between coefficients $b$ and $c$ and sand diameter $d_{\text {sand }}$

It is shown in the figure that $a, b$ and $c$ are all dependent on the sand particle size $d_{\text {sand }}($ refer to $\mathrm{Eq},(8)$ and Figure 10). Note that coefficient $a$ increases as $d_{\text {sand }}$ increases in a linear relationship, while the case for coefficient $b$ and $c$ is opposite. The coefficients $b$ and $c$ linearly decrease as $d_{\text {sand }}$ increasing. A sensibility analysis for effect of variation of these three coefficients on the sigmoid curve (logistic function) is applied to interpret the growth mode of $\tau^{*}$ as a result of space filling in Figure 11. It shows that coefficients $a$ and $b$ are indicators of shape of the curve but they vary at driving the curve shift positively or negatively given a constant $c$ value (Figure 11 (a), (b)). The coefficient $c$ controls the equilibrium value of the $\tau^{*}$ at constant values of $a$ and $b$ (Figure 11 (c)). Note that the threshold shear stress of G4 mixtures experience a rapid ascent (see Figure 6 (d)) with increasing mud content owing to the largest $a$ value and smallest $b$ value in four mixtures. Thus the model reveals a stronger binding force for coarse sand and clay mixture by quantifying these coefficients, which agrees with the observations of erosion threshold in the present tests.

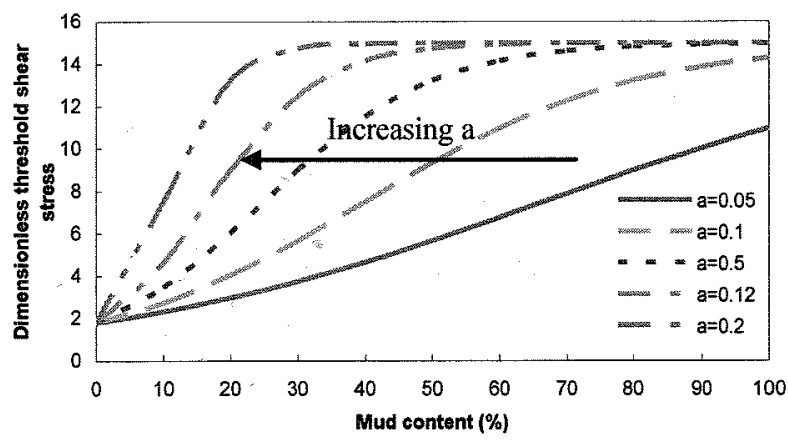

(a) a ranges from 0.05 to $0.2(b=2, c=15)$

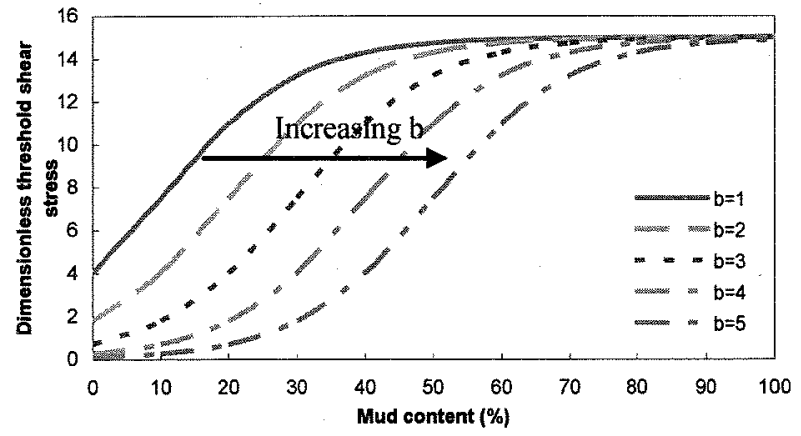

(b) b ranges from 1 to $5(a=0.1, c=15)$ 


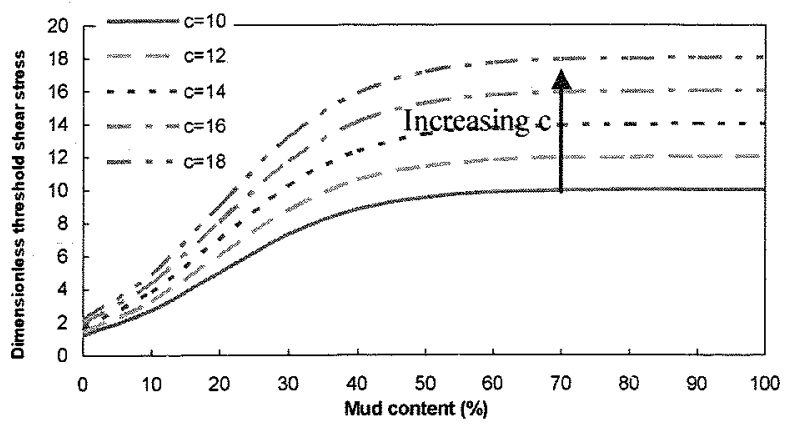

(c) c ranges from 10 to $18(a=0.1, b=2)$

Figure 11 Sensibility analysis on effect of coefficients $a, b$ and $\mathrm{c}$ on sigmoid curve

The experimental results are plotted in the form of Shields parameter $\theta_{\mathrm{cr}}$ against dimensionless grain size $D_{*}$, as shown in Figure 12. The values of $\theta_{\mathrm{cr}}$ of four groups of mixtures are higher than the results gained from Shields curve (black line) except for the samples with sand only. Thus the classical Shields diagram underestimates the threshold of motion for sand and mud mixtures in present research, because the cohesion force is not considered in the Shields curve.

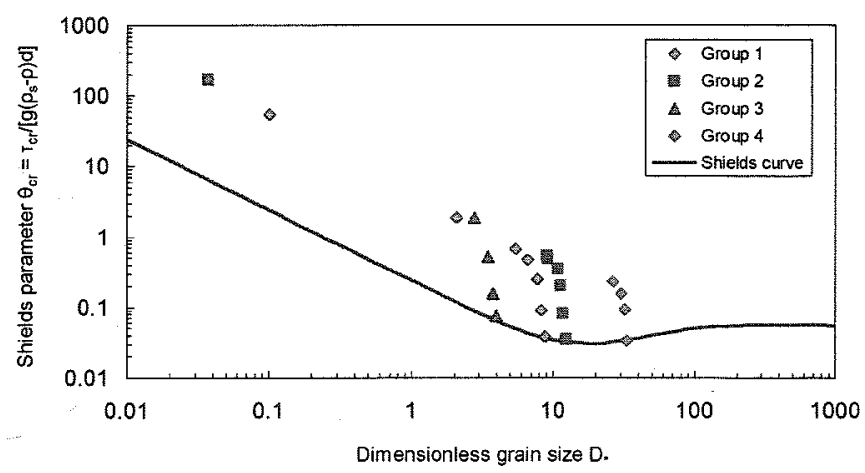

Figure 12 Threshold of motion of mixtures compared with Shields diagram

The dimensionless shear stress $\tau^{*}$ obtained from logistic function is plotted against $\tau^{*}$ measured in the present experiments in Figure 13. A considerable agreement has been achieved with error range between $\pm 30 \%$. Thus the logistic curve is able to model mud content effect on characteristics of the erosion threshold of reconstituted mixtures under moderate consolidation $\left(\alpha_{c}=2.0\right)$.

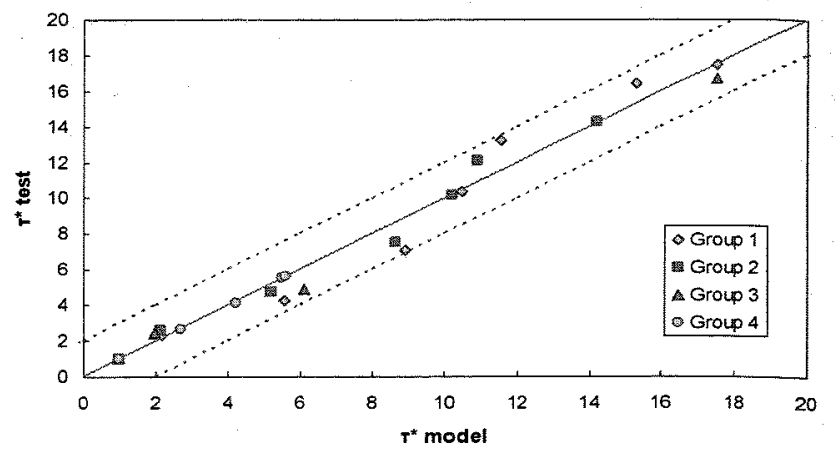

Figure 13 Comparison between $\mathrm{r}^{*}$ obtained from model and tests

\section{CONCLUSIONS}

The threshold motion of cohesive sediment has been analysed based on underlying physics and a logistic function was proposed considering the effects of cohesive material content, interaction of coarse and fine grains under a moderate consolidation condition. A dimensionless critical shear stress $\tau^{*}$ was proposed in terms of ratio of critical shear stress of mixed sediment $\tau_{\mathrm{cr}}$ over non-cohesive component $\tau_{\mathrm{s}}$. The $\tau^{*}$ is actually a comprehensive coefficient $k$ in the present test, and the $k$ is determined by conducting four sets of experiments on four different reconstituted sands and kaolin clay reconstituted mixtures. The results of the erosion threshold test showed a strong dependence on the increasing mud content in the form of a sigmoid shaped growth, which can be expressed by a logistic function. The coefficients of the logistic function $a, b$ and $c$ were obtained from regression analysis of experimental data. The proposed model well depicts the growing stages of erosion threshold shear stress with added mud content and interprets the space-filling variation as coarse particle size changes.

The present tests investigated the erosion behaviour of reconstituted mixtures under moderate consolidation with one fine material added. It provides reference for further research on sediment erosion behaviour under different consolidation situations and mixtures with various sorts of fine particle.

\section{ACKNOWLEDGEMENTS}

This research is financially supported by CSC-UWA scholarship, top-up scholarship from Australia-China Natural Gas Technology Partnership Fund. The authors would also like to thank Frank Tan, Wayne Galbraith and Philip Hortin at the electronic and mechanical workshops of the University of Western Australia (UWA) for their respective parts in experimental apparatus setup. In addition, the assistance from Binaya Bhattarai, Ying Guo and Claire Bearman in the soil laboratory of UWA is much appreciated. 


\section{REFERENCES}

Allersma, E., 1988. Morfologisch onderzoek Noordelijk Deltabekken. Morfologische modellering deel IV: Composition and Density of Sediments (in Dutch) (Report Z71.03). Delft WL|Delft Hydraulics.

ASCE, 1968. "Erosion of cohesive sediments." by the Task Committee on Erosion of Cohesive Materials. Journal of the hydraulics division, proceedings of the American Society of Civil Engineers, Vol. 94, No. HY4, 1017-1049.

Australian Standard, 1995. Methods of testing soils for engineering purposes-Soil classification tests-Determination of the soil particle density of a soil-Standard method, AS 1289.3.5.1-1995, Sydney, Australia.

Australia Standard, 1994. Determination of the particle size distribution of a soil-Standard method of fine analysis using a hydrometer, AS 1289.3.6.3-1994, Sydney, Australia.

Australia Standard, 1991. Methods of testing soils for engineering purposes-Method 3.9: Soil classification testsDetermination of the cone liquid limit of a soil, AS 1289.3.91991, Sydney, Australia.

Australia Standard, 1995. Methods of testing soils for engineering purposes-Method 3.2.1: Soil classification testsDetermination of the plastic limit of a soil-Standard method, AS 1289.3.9-1995, Sydney, Australia.

Australian Standard, 1995. Methods of testing soils for engineering purposes-Method 3.6.2: Soil classification testsDetermination of the particle size distribution of a soil-Analysis by sieving in combination with hydrometer analysis (subsidiary method). AS 1289.3.6.2-1995, Sydney, Australia.

Christoffersen, J.B. and Jonsson, I.G., 1985. Bed friction and dissipation in a combined current and wave motion. Ocean Engineering, 12(5), 387-423.

Dou, G. R., 2000. Incipient motion of sediment under currents. China Ocean Engineering. Vol. 14, No. 4, pp. 391-406.

Mehta, A.J., Say-Chong Lee., 1994. Problems in linking the threshold condition for the transport of cohesionless and cohesive sediment grain. Journal of Coastal Research 10 (1), pp.170-177.

Mitchener, H., Torfs, H., 1996. Erosion of mud/sand mixtures. Coastal Engineering, 29:1-25.

Panagiotopoulos, I., Voulgaris, G., , Collins, M. B., 1997. The influence of clay on the threshold of movement of fine sandy beds. Coastal Engineering 32 (1), pp. 19-43
Righetti, M, Lucarelli, C., 2007. May the Shields theory be extended to cohesive and adhesive benthic sediments. Journal of Geophysical Research C: Oceans 112 (5), art. No. C05039.

Shields, A., 1936. Application of similarity principles and turbulence research to bedload movement, Mitteilunger der Preussischen Versuchsanstalt fur Wasserbau und Schiffbau, vol. 26, pp. 5-24.

Soulsby, R., 1997 Dynamics of Marine Sands, Thomas Telford, London. pp. 99-106.

Ternat, F., Boyer, P., Anselmet, F., and Amielh, M., 2008. Erosion threshold of saturated natural cohesive sediments: Modelling and experiments. Water Resources Research, 44 (11). art. no. W11434.

Torfs, H. Jiang, J., and Mehta, A. J., 2000. Assessment of the erodibility of fine/coarse sediment mixtures. In: Coastal and Estuarine Fine Sediment Processes, W.H. McAnally and Mehta, A.J. (Ed.), Elsevier, Oxford, UK. pp. 109-123.

Tan G. M., Wang J., Shu, C. W. Lai, Y. H., 2007. Effects of consolidation time and particle size on scour rateds of cohesive sediment. Journal of Hydrodynamics, Ser. B Volume 19, Issue 2, April 2007, pp 160-164.

Van Ledden, M., Van Kesteren, W.G.M., Winterwerp, J.C., 2004. A conceptual framework for the erosion behaviour of sand-mud mixtures. Continental Shelf Research 24 (1), pp. 111.

Van Rijn, L.C., 1993. Principles of Sediment Transport in Rivers, Estuaries and Coastal Seas. Aqua Publications, Amsterdam.

Van Rijn, L.C., 2007. Unified View of Sediment Transport by Currents and Waves. I: Initiation of Motion, Bed Roughness, and Bed-Load Transport Journal of Hydraulic Engineering, 133 (6), pp. 649-667.

Verhulst, P. F., 1845. Recherches mathématiques sur la loi d'accroissement de la population. Nouv. mém. de l'Academie Royale des Sci. et Belles-Lettres de Bruxelles 18, 1-41. 